\title{
Socioeconomic disadvantage, fetal environment and child development: linked Scottish administrative records based study
}

\author{
Christopher James Playford ${ }^{1 *}$, Chris Dibben ${ }^{2,3}$ and Lee Williamson ${ }^{3}$
}

\begin{abstract}
Background: Cognitive development in childhood is negatively affected by socioeconomic disadvantage. This study examined whether differences in fetal environment might mediate the association between family socioeconomic position and child development.

Methods: Data were linked from the Scottish Longitudinal Study, maternity inpatient records and the Child Health Surveillance Programme - Pre School for 32,238 children. The outcome variables were based on health visitor assessment of gross motor, hearing and language, vision and fine motor, and social development. Socioeconomic position was measured using parental social class and highest qualification attained. Random-effects logistic regression models were estimated to account for multiple reviews and familial clustering. Mediation analysis was conducted using the Karlson-Holm-Breen method.

Results: Hearing and language, vision and fine motor, and social development were associated with lower parental social class and lower parental educational qualifications after adjustment for fetal environment. Fetal environment partially mediated the estimated effect of having parents without educational qualifications for hearing and language $(\beta=0.15 ; 95 \%$ confidence interval $(C l)=0.07,0.23)$, vision and fine motor $(\beta=0.19 ; C l=0.10,0.28)$ and social development ( $\beta=0.14 ; C l=0.03$ to 0.25 ).

Conclusions: Socioeconomic position predicted hearing and language, vision and fine motor, and social development but not gross motor development. For children of parents without educational qualifications, fetal environment appears to contribute to a part of the socioeconomic gradient in child development abnormalities but post-natal environment appears to still explain the majority of the gradient and for other children most of it.
\end{abstract}

Keywords: Birth weight, Lifecourse/childhood circumstances, Child health, Health inequalities, Socioeconomic

\section{Background}

The cognitive and emotional development of children growing up in circumstances of socioeconomic disadvantage is more likely to be abnormal compared to children raised in more advantaged families [1]. This association has been noted for a range of different developmental attributes including gross motor skills [2], vision and fine motor skills [3], social development [4] and hearing and

\footnotetext{
* Correspondence: c.jplayford@exeter.ac.uk

'Department of Sociology, University of Exeter, Exeter, UK

Full list of author information is available at the end of the article
}

language development [5]. Atypical child development outcomes are also associated with low birthweight (LBW) [6] including significant motor impairment [7], conductive hearing loss [8], and a wider spectrum of social and behavioural difficulties $[9,10]$. Infants born preterm are more likely to have development problems. A large proportion of extremely preterm children will experience significant development delay, cognitive impairments, learning disabilities, and behavioural and emotional problems [11]. Preterm children are also more likely to have fine motor development problems [12]. 
The aim of this study was to examine the extent to which differences in fetal environment mediate the association between socioeconomic position and child development. Few studies have simultaneously evaluated the role of other determinants of child development [13]. Previous studies have identified that birthweight is associated with family socioeconomic position with the children of parents in manual occupations being more likely to have low or very low birthweight $[14,15]$. Our measure of fetal environment include a range of variables which represent pregnancy and delivery complications (including birthweight and preterm birth), mother's behaviour and the physical condition of the new born child. Birthweight is associated with family socioeconomic position [14, 15]. We hypothesised that children born to disadvantaged parents would be more likely to have developmental abnormalities but that this would be partially mediated by a poorer fetal environment among more disadvantaged families.

\section{Methods \\ Sample}

The data analysed includes a number of administrative datasets linked to the Scottish Longitudinal Study (SLS) by NHS Scotland Information Services Division (ISD). The SLS is a $5.3 \%$ representative sample of the Scottish population which links Census records (from 1991, 2001 and 2011) to other administrative data resources [16]. In this study, the linked administrative datasets include the Scottish Morbidity Record maternity inpatient and day case dataset (SMR02) and the Child Health Surveillance Programme - Pre School dataset (CHSP-PS). Details of the linkage are presented in Fig. 1. The mothers of SLS members were identified in the SMR maternity dataset (SMR02) [17]. The sample included all SLS members born from 1991 to 2001 and the children of female SLS members who were born between 1991 and 2005. For both groups, only singleton births were included. Using the relationships between SLS members identified through the Census, it was then possible to include information relating the sex and ethnicity of the individual and their parental occupational classification and parental highest qualification. Not all records were linkable because of the coverage of the CHSP-PS data available, ${ }^{1}$ availability of parental information from the census, and non-response within the datasets. The majority of nonresponse is due to the geographical coverage of the CHSP-PS reviews and differential reviews by area, and therefore was expected. We argue that this is not biasing these results as the nonresponse is random with regard to the outcomes of interest (this will be discussed further in the limitations).

\section{Measures}

The Child Health Surveillance Programme - Pre-School dataset (CHSP-PS) contains indicators of development which relate to gross motor, hearing and language, vision and fine motor, and social development based on the Woodside system [18]. The classification is based on assessment by a health visitor of the expected progress of children against a series of criteria which are based on the ability of the child to complete a series of tasks [19]. The criteria vary according to the age of the child being assessed. Details of each age-specific assessment are provided in the Child Health Surveillance Programme PreSchool Clinical Guidelines produced by NHS Scotland [19]. Participants are classified as either normal, incomplete, doubtful/uncertain or abnormal. ${ }^{2}$ Doubtful is suggestive of a possible abnormality, rather than an improper response. There are multiple reviews per individual (see Additional file 1: Table S1) and the classification of a child may vary between reviews. The total number of reviews is greater for assessment of Gross Motor and Hearing $(114,928)$ than for Vision and Fine Motor and Social $(93,481)$ because this is recorded in one extra review, the 6-8 week review.

Parental occupation is classified using National Statistics Socio Economic Class (NS-SEC). Analysis has been restricted to natural parents, with legal step-parents excluded. It was decided to use the higher ranking of father's or mother's occupation as indicative of familial circumstances. NS-SEC was selected as the measure of socioeconomic position because it is explicitly based the conditions and relations of employment associated with the occupation of an individual [20]. This reflects the material circumstances of the family including the nature of payment contract, prospects for promotion and level of autonomy which are all indicative of socioeconomic position [20]. It is used in all official statistics and surveys in the UK and is a robust and comparable measure.

Parental education is classified using the highest qualification gained, based on the 2001 census. This has been included in these analyses because it captures a different aspect of socioeconomic position, particularly knowledge, skills and the longer term influence of early life circumstances [21]. Sex and ethnicity are recorded in the 2001 census. Ethnicity was not included as an independent variable in the models because the high number of ethnic groups with a low frequency preclude meaningful comparison.

The Maternity Inpatient and Day Case data contains variables recorded at birth including maternal marital status, maternal height, maternal age, maternal smoking status, mode of delivery, parity, APGAR score, birthweight, and estimated gestation. Birthweight percentiles were calculated to control for any changes in the distribution of birthweight over time. Between 1980 and 2003 the proportion of infants born LBW $(<2500 \mathrm{~g})$ has remained broadly consistent but the mean birthweight 


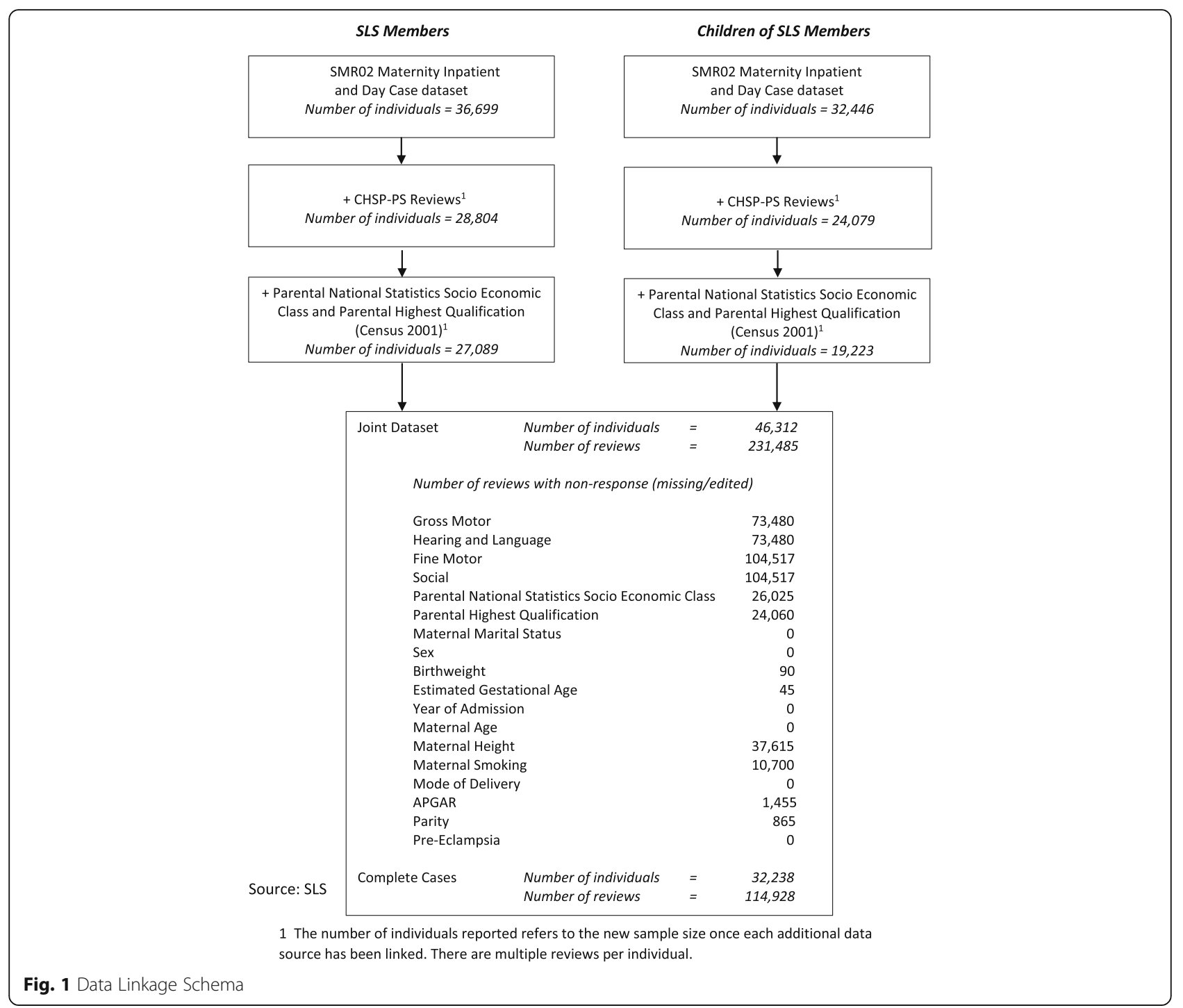

in Scotland has increased [22]. Birthweight centiles were constructed stratified by completed week of estimated gestation and sex based on the sample. When calculating birthweight percentiles, we excluded cases where estimated gestation was less than 32 weeks (i.e. extremely or very preterm) because of a lack of cases. Sensitivity analysis was conducted by estimating the models using birthweight (categorised as $<1500$ g (Very Low), 1500$2500 \mathrm{~g}$ (Low) or $>2500 \mathrm{~g}$ in line with World Health Organisation guidelines) instead of birthweight percentiles (see Additional file 1: Table S4). Gestational age was divided into three categories (under 32 weeks, 3237 weeks, 37 weeks or more) to correspond with definitions of very preterm, preterm and early/full-term [23].

\section{Analyses}

The analysis uses a longitudinal design because there were multiple development reviews recorded per child.
Random-effects models were fitted because they were more efficient, using all available information from the sample, and also control for unobserved heterogeneity by removing time-invariant error components from the model (i.e. omitted variables).

Two random-effects logistic regression models were estimates for each child development outcome (gross motor, hearing and language, vision and fine motor, and social development) using Stata v13. The first model included parental NS-SEC, parental highest qualification and maternal marital status. The second model included the same variables plus birthweight percentile, estimated gestational age, sex, maternal smoking history, mode of delivery, APGAR score, parity, year of admission, maternal age, maternal height, and pre-eclampsia indicator. Estimates were corrected for familial clustering because the sample included SLS members and the children of SLS members (i.e. siblings were present). 
Mediation analysis was conducted using the KarlsonHolm-Breen (KHB) method [24] to decompose the total effect of a socioeconomic measure on the developmental outcome into the direct effect (operating purely via the socioeconomic variable) and the indirect effect (i.e. due to a poorer fetal environment). Unlike linear regression models, direct comparison of the estimated effect sizes is not possible between two logistic regression models because of the fixed variance of the residual. The KHB method works by rescaling the models to ensure comparability. This approach is advantageous because it permits the inclusion of multiple mediators while holding other covariates constant [24].

We therefore specified the KHB models to directly match the approach used in the random-effects modelling. We decomposed the total effect of each socioeconomic variable (parental NS-SEC, parental highest qualification and maternal marital status) on each child development measure (gross motor, hearing and language, vision and fine motor, and social development) into the direct effect and the indirect effect (operating via the fetal environment: birthweight percentile, estimated gestational age, sex, maternal smoking history, mode of delivery, APGAR score, parity, year of admission, maternal age, maternal height, and pre-eclampsia indicator). In the administrative data we have a number of measures of fetal environment: prematurity (estimated gestation), restricted growth (birthweight percentiles), mother's smoking and a measure of the physical condition of the new born child. These indicators will measure, to some extent, the same causes. This not a problem for this analysis because we are using them together to try and estimate the total impact of fetal exposure to environmental insult and shocks associated with maternal socioeconomic status. We are not trying to attribute this to one particular pathway. We specifically included the group of variables together because we wished to estimate the indirect effect of all of these outcomes simultaneously on the socioeconomic variables.

The hypothesised temporal ordering of the variables is relevant to the mediation model. In this study, parental NS-SEC has been recorded after the birth of the child. We argue that social class as a measure is indicative of long-term socioeconomic position and has been designed to represent a more stable and enduring feature of lifetime circumstances than purely the occupation recorded at time of the census [25], and that this is better recorded later in life as occupational maturity is reached. This analysis uses the higher class position of the parents, which we argue is a better approximation of family circumstances. Parental highest qualification is likely to have been achieved prior to the birth of the child and is also indicative of long-term socioeconomic position.

\section{Results}

Table 1 reports the characteristics of the baseline sample in frequency of reviews. 114,928 Reviews of gross motor and hearing and language development were recorded for 32,238 individuals. The number of reviews of vision and fine motor and social development was lower (93,481 reviews) because these were not reviewed at the 6-8 week review (see Additional file 1: Table S1). There are notable differences in parental socioeconomic position between children with abnormal or doubtful development compared to those with normal development across all indicators. Children with abnormal or doubtful development tend to have parents in less advantaged occupational positions (for all four indicators the $p$-value is less than 0.001, based on Cuzick's nonparametric test for trend in ordinal data ${ }^{3}$ ). A similar pattern exists by parental highest qualification.

Table 2 reports models predicting gross motor, hearing and language, vision and fine motor, and social development. Two models are estimated for each outcome which include measures of social background plus fetal environment. ${ }^{4}$ The patterning of socioeconomic disadvantage varies by child development measure (see Fig. 2). Parental NS-SEC was not associated with gross motor but was predictive of hearing and language, vision and fine motor, and social development. Before adjustment for fetal environment, children whose parents were in semi-routine (NS-SEC 6; OR $=2.18 ; \mathrm{CI}=1.49,3.19$ ) and routine occupations (NS-SEC 7; $\mathrm{OR}=2.34 ; \mathrm{CI}=1.56$, 3.52 ) were more likely to have abnormal or doubtful vision and fine motor development than those with parents in higher managerial or professional occupations (NS-SEC 1.1).

Deficiencies in hearing and language and social development were noted for a wider range of parental NSSEC classes than for vision and fine motor development. Children whose parents were small employers and own account workers (NS-SEC 4; OR $=1.53 ; \mathrm{CI}=1.19,1.96$ ), in lower supervisory and technical occupations (NS-SEC 5 ; $\mathrm{OR}=1.55 ; \mathrm{CI}=1.23,1.95)$, semi-routine occupations (NS-SEC 6; OR $=1.70 ; \mathrm{CI}=1.37,2.11$ ) and routine occupations (NS-SEC 7; $\mathrm{OR}=1.67 ; \mathrm{CI}=1.32,2.12$ ) were more likely to have abnormal or doubtful hearing and language development than those with parents in higher managerial or professional occupations, prior to adjustment for fetal environment (NS-SEC 1.1). Social development followed a similar pattern.

For all four development measures, children with parents that had never worked or were long-term unemployed were more likely to exhibit abnormal or doubtful development than those with parents in higher managerial professional occupations in models which were unadjusted for fetal environment. This was true for gross motor $(\mathrm{OR}=1.70 ; \mathrm{CI}=1.03,2.80)$, hearing and 


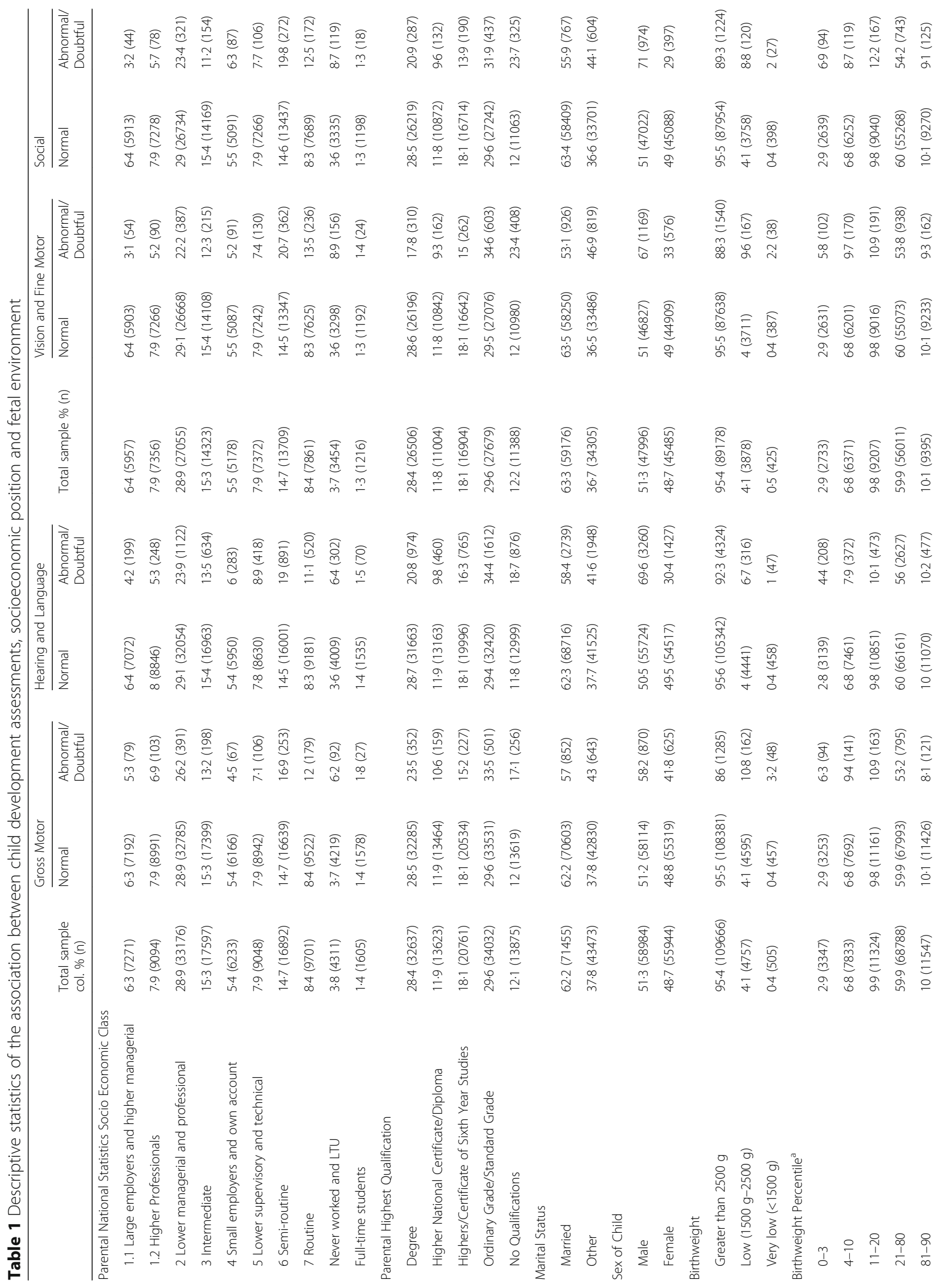




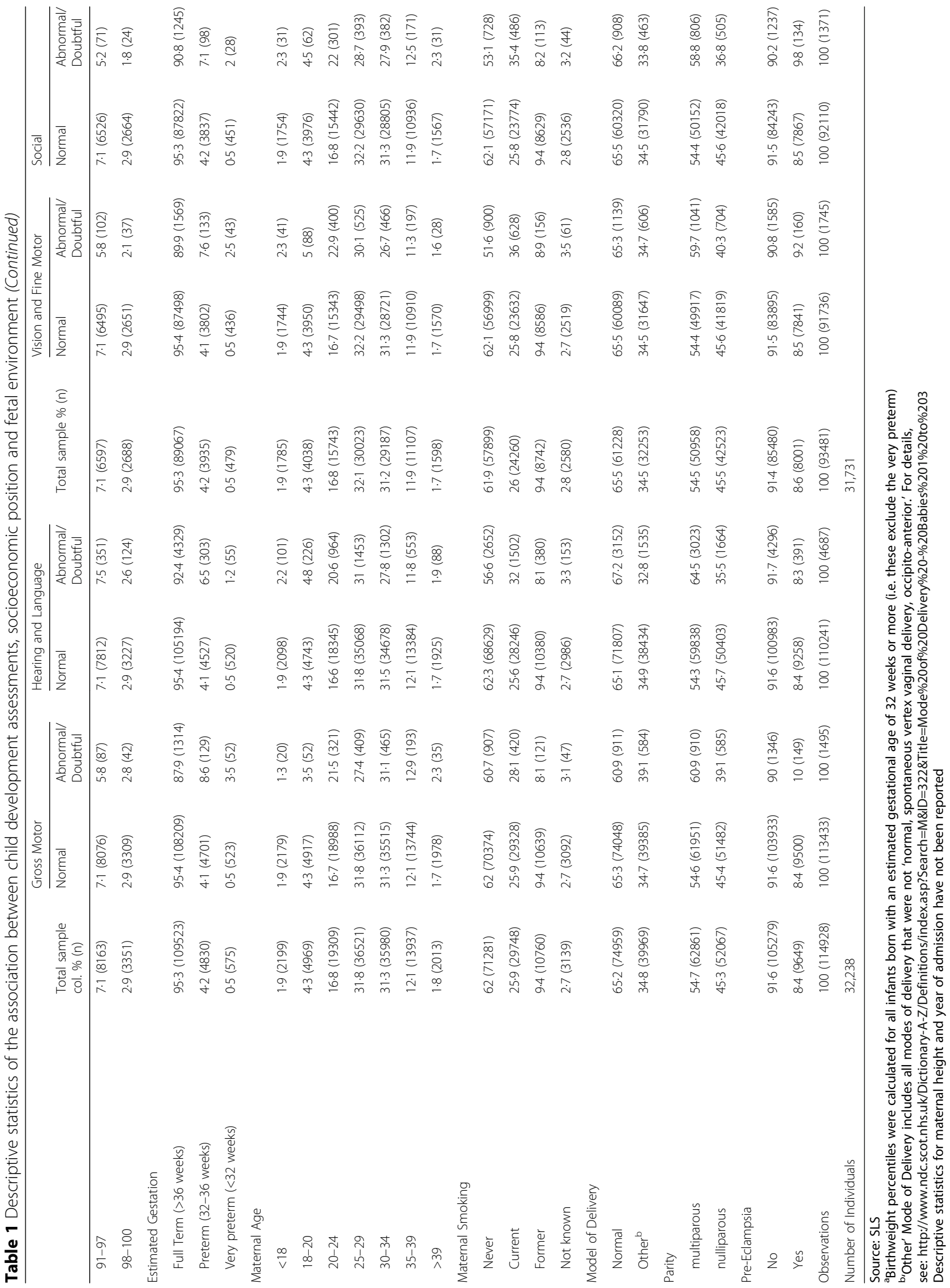




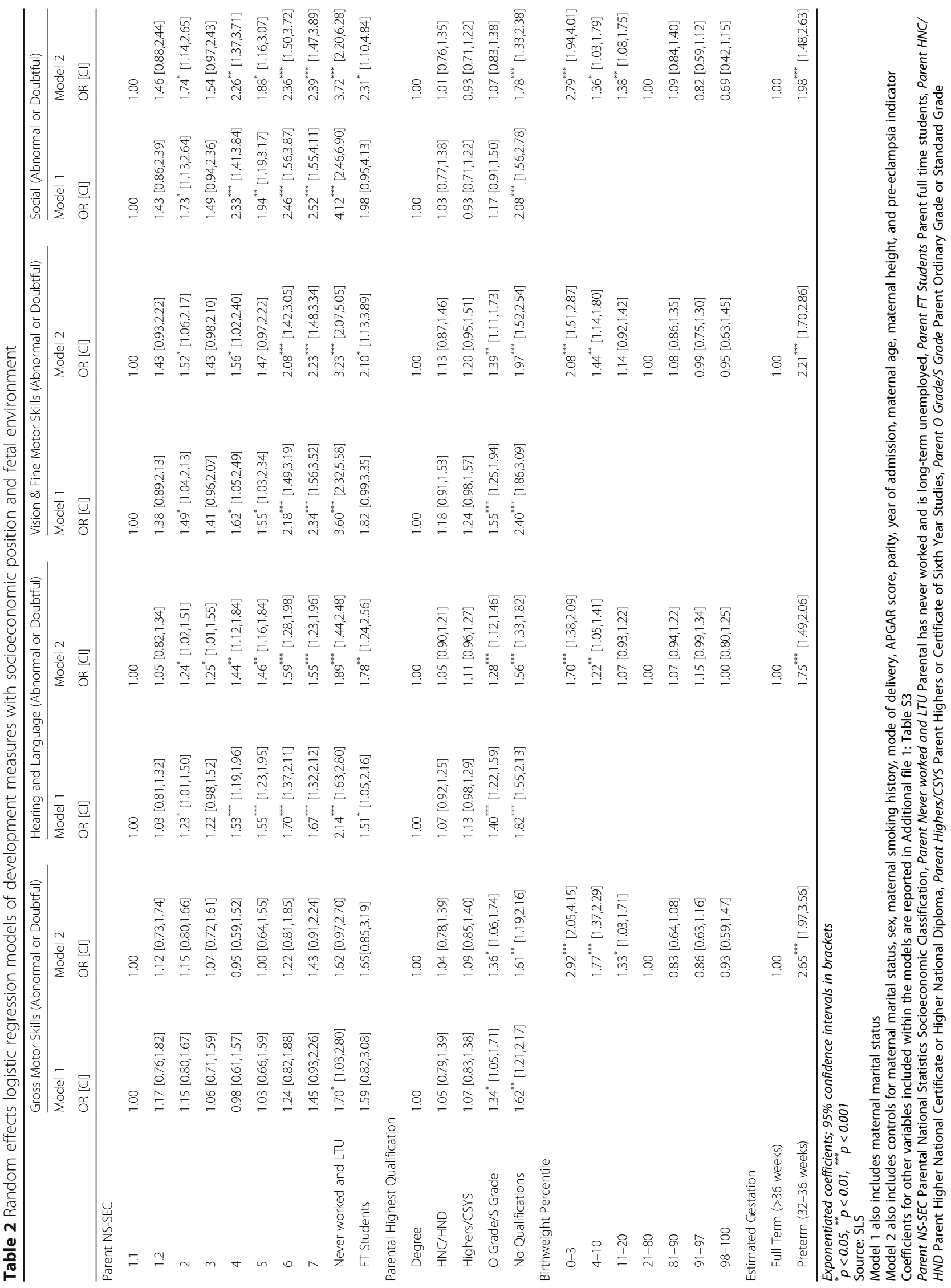


Child Development Assessments

Random-effects Model Estimates (Abnormal or Doubtful)
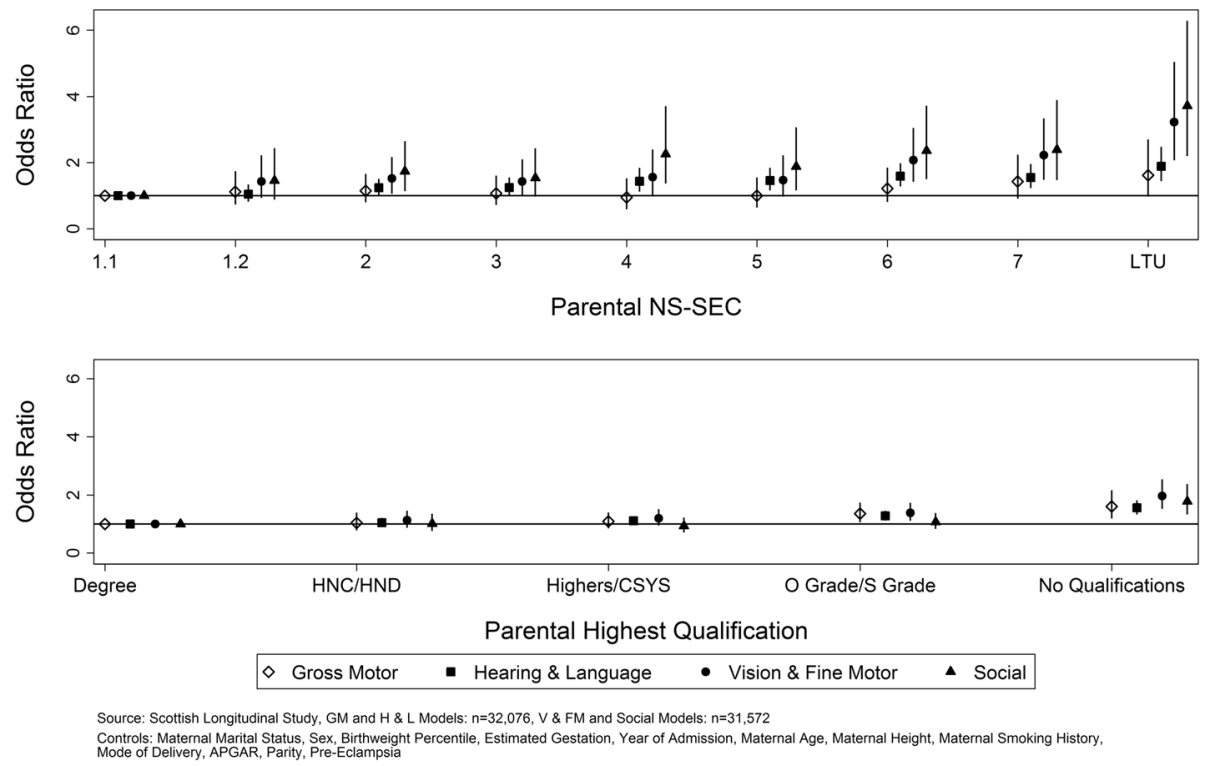

Fig. 2 Random effects logistic regression models of development measures and socioeconomic position

language $(\mathrm{OR}=2.14 ; \mathrm{CI}=1.63,2.80)$, vision and fine motor $(\mathrm{OR}=3.60 ; \mathrm{CI}=2.32,5.58)$, and social development $(\mathrm{OR}=4.12 ; \mathrm{CI}=2.46,6.90)$. Children with parents without educational qualifications were more likely than those who parents had a degree to exhibit abnormal or doubtful gross motor $(\mathrm{OR}=1.62 ; \mathrm{CI}=1.21,2.17)$, hearing and language $(\mathrm{OR}=1.82 ; \mathrm{CI}=1.55,2.13)$, vision and fine motor $(\mathrm{OR}=2.40 ; \mathrm{CI}=1.86,3.09)$, and social development $(\mathrm{OR}=2.08 ; \mathrm{CI}=1.56,2.78)$ in models which did not adjust for fetal environment.

Infants born in the 0-3rd gestational-age specific percentile for birthweight, were more likely to experience abnormal or doubtful gross motor development $(\mathrm{OR}=$ 2.92; $\mathrm{CI}=2.05,4.15)$, hearing and language $(\mathrm{OR}=1.70$; $\mathrm{CI}=1.38,2.09)$, vision and fine motor $(\mathrm{OR}=2.08 ; \mathrm{CI}=$ $1.51,2.87)$, and social development $(\mathrm{OR}=2.79 ; \mathrm{CI}=$ 1.94). The effect size was smaller for infants born in the 4th-10th percentiles. We did not observe a greater risk for infants whose gestational-age specific birthweight percentile is above average. Similar results are reported when the analysis was performed using absolute measures of birthweight (see Additional file 1: Table S4). There was also clear association between pre-term birth and gross motor development $(\mathrm{OR}=2.65 ; \mathrm{CI}=$ $1.97,3.56)$, hearing and language $(\mathrm{OR}=1.75, \mathrm{CI}=$ $1.49, \mathrm{CI}=2.06)$, vision and fine motor $(\mathrm{OR}=2.21$; $\mathrm{CI}$ $=1.70,2.86)$, and social development $(\mathrm{OR}=1.98 ; \mathrm{CI}=$ 1.48, 2.63) (Table 2).

The inclusion of fetal environment measures did not attenuate greatly the association between socioeconomic disadvantage and child development outcomes. For example, when adjusting for fetal environment, the risk of abnormal or doubtful development decreased slightly among children whose parents had never worked or were long term unemployed for gross motor skills (Model 1 $\mathrm{OR}=1.70 ; \mathrm{CI}=1.03,2.80 ;$ Model $2 \mathrm{OR}=1.62 ; \mathrm{CI}=0.97$, 2.70), hearing and language (Model $1 \mathrm{OR}=2.14 ; \mathrm{CI}=1.63$, 2.80; Model $2 \mathrm{OR}=1.89 ; \mathrm{CI}=1.44,2.48)$, vision and fine motor skills (Model $1 \mathrm{OR}=3.60 ; \mathrm{CI}=2.32,5.58$; Model 2 $\mathrm{OR}=3.23 ; \mathrm{CI}=2.07,5.05)$, and social development (Model $1 \mathrm{OR}=4.12$; $\mathrm{CI}=2.46,6.90$; Model $2 \mathrm{OR}=3.72$; $\mathrm{CI}=2.20,6.28$ ), and (Table 2). For robustness, we used the Karlson-Holm-Breen (KHB) method to decompose the total effects observed into direct effects (operating purely via the socioeconomic variable) and indirect effects (i.e. via the fetal environment measures, see Table 3). For the majority of parental NS-SEC classes and levels of parental qualifications, the contribution of indirect effects (i.e. via differential fetal environment) were minimal. However for children in households with parents who have never worked or who have no educational qualifications, around a quarter of the effect associated with socioeconomic status appears to be related to the fetal environment measures (based on comparison of indirect effect with total effect, see Table 3).

As part of a wider sensitivity analysis, we also investigated whether there were differentials in the association by the sex of the child (see Additional file 1: Tables S8 and S9). The effect size for socioeconomic position variables for males and females were broadly consistent with the main-effects models estimated in Table 2. 
Table 3 The pathway from parental socioeconomic position to abnormal/doubtful child development via birth factors ${ }^{2}$

\begin{tabular}{|c|c|c|c|c|}
\hline & Gross Motor Skills & Hearing \& Language & Vision \& Fine Motor Skills & Social \\
\hline & $\beta[\mathrm{Cl}]$ & $\beta[\mathrm{Cl}]$ & $\beta[\mathrm{Cl}]$ & $\beta[\mathrm{Cl}]$ \\
\hline \multicolumn{5}{|l|}{ Parent NS-SEC } \\
\hline \multicolumn{5}{|c|}{1.2 Higher Professionals } \\
\hline Total effect & $0 \cdot 14[-0 \cdot 27,0 \cdot 55]$ & $0.02[-0 \cdot 21,0.26]$ & $0.33[-0.09,0.75]$ & $0 \cdot 37[-0 \cdot 11,0 \cdot 85]$ \\
\hline Direct effect & $0 \cdot 13[-0 \cdot 28,0 \cdot 54]$ & $0.05[-0 \cdot 18,0 \cdot 29]$ & $0.38[-0.05,0 \cdot 80]$ & $0.40[-0 \cdot 08,0 \cdot 89]$ \\
\hline Indirect effect & $0.01[-0.05,0.07]$ & $-0.03[-0 \cdot 10,0 \cdot 04]$ & $-0.05[-0.13,0 \cdot 03]$ & $-0.03[-0 \cdot 12,0.06]$ \\
\hline \multicolumn{5}{|c|}{2 Lower managerial and professional } \\
\hline Total effect & $0 \cdot 14[-0 \cdot 20,0 \cdot 48]$ & $0.20[0.01,0 \cdot 39]$ & $0.43[0.08,0 \cdot 78]$ & $0.57[0 \cdot 16,0 \cdot 97]$ \\
\hline Direct effect & $0 \cdot 16[-0 \cdot 18,0 \cdot 50]$ & $0.22[0.03,0 \cdot 40]$ & $0.45[0 \cdot 10,0 \cdot 80]$ & $0.59[0 \cdot 19,1 \cdot 00]$ \\
\hline Indirect effect & $-0.02[-0.08,0 \cdot 04]$ & $-0.02[-0.09,0.05]$ & $-0.02[-0 \cdot 10,0 \cdot 06]$ & $-0.02[-0 \cdot 11,0 \cdot 07]$ \\
\hline \multicolumn{5}{|l|}{3 Intermediate } \\
\hline Total effect & $0.05[-0 \cdot 32,0 \cdot 43]$ & $0.20[-0.01,0.40]$ & $0.37[-0.01,0.75]$ & $0.44[-0 \cdot 01,0 \cdot 88]$ \\
\hline Direct effect & $0.09[-0 \cdot 29,0 \cdot 47]$ & $0 \cdot 22[0 \cdot 02,0 \cdot 43]$ & $0.40[0.02,0 \cdot 78]$ & $0.47[0.03,0.92]$ \\
\hline Indirect effect & $-0.04[-0 \cdot 11,0 \cdot 03]$ & $-0.03[-0 \cdot 10,0.04]$ & $-0.02[-0.11,0.06]$ & $-0.03[-0.13,0 \cdot 06]$ \\
\hline \multicolumn{5}{|c|}{4 Small employers and own account } \\
\hline Total effect & $-0.01[-0 \cdot 47,0 \cdot 44]$ & $0.43[0 \cdot 19,0 \cdot 67]$ & $0.53[0 \cdot 10,0 \cdot 96]$ & $0.90[0 \cdot 41,1 \cdot 39]$ \\
\hline Direct effect & $0.00[-0.46,0.45]$ & $0.37[0.13,0 \cdot 61]$ & $0.50[0.06,0.93]$ & $0.87[0.38,1 \cdot 36]$ \\
\hline Indirect effect & $-0.01[-0.08,0 \cdot 06]$ & $0.06[-0.01,0 \cdot 14]$ & $0.04[-0 \cdot 05,0 \cdot 12]$ & $0.03[-0 \cdot 07,0 \cdot 12]$ \\
\hline \multicolumn{5}{|c|}{5 Lower supervisory and technical } \\
\hline Total effect & $0.03[-0 \cdot 38,0 \cdot 45]$ & $0.42[0 \cdot 20,0 \cdot 65]$ & $0.46[0.05,0.87]$ & $0 \cdot 68[0 \cdot 20,1 \cdot 15]$ \\
\hline Direct effect & $0 \cdot 05[-0 \cdot 37,0 \cdot 47]$ & $0.38[0 \cdot 16,0 \cdot 61]$ & $0.43[0.02,0 \cdot 84]$ & $0.67[0 \cdot 19,1 \cdot 14]$ \\
\hline Indirect effect & $-0.02[-0 \cdot 10,0 \cdot 06]$ & $0.04[-0 \cdot 04,0 \cdot 12]$ & $0.03[-0.06,0 \cdot 12]$ & $0.01[-0.09,0 \cdot 11]$ \\
\hline \multicolumn{5}{|l|}{6 Semi-routine } \\
\hline Total effect & $0.20[-0 \cdot 18,0 \cdot 59]$ & $0.52[0.31,0.73]$ & $0.81[0.43,1 \cdot 19]$ & $0.94[0.49,1 \cdot 38]$ \\
\hline Direct effect & $0.25[-0 \cdot 14,0 \cdot 63]$ & $0 \cdot 47[0 \cdot 26,0 \cdot 68]$ & $0.79[0 \cdot 41,1 \cdot 18]$ & $0.94[0.49,1.39]$ \\
\hline Indirect effect & $-0.04[-0 \cdot 13,0 \cdot 04]$ & $0.05[-0.03,0 \cdot 13]$ & $0.02[-0.07,0 \cdot 11]$ & $0.00[-0 \cdot 11,0 \cdot 10]$ \\
\hline \multicolumn{5}{|l|}{7 Routine } \\
\hline Total effect & $0.35[-0.06,0.77]$ & $0.51[0 \cdot 28,0 \cdot 73]$ & $0.89[0 \cdot 49,1 \cdot 29]$ & $0.95[0.48,1 \cdot 42]$ \\
\hline Direct effect & $0.40[-0.01,0.82]$ & $0.44[0 \cdot 21,0 \cdot 67]$ & $0.86[0 \cdot 46,1 \cdot 27]$ & $0.94[0.47,1 \cdot 42]$ \\
\hline Indirect effect & $-0.05[-0 \cdot 14,0 \cdot 04]$ & $0.06[-0.02,0 \cdot 14]$ & $0.03[-0 \cdot 06,0 \cdot 13]$ & $0.01[-0 \cdot 10,0 \cdot 12]$ \\
\hline \multicolumn{5}{|c|}{ Never worked and Long Term Unemployed } \\
\hline Total effect & $0.51[0.04,0 \cdot 99]$ & $0.78[0.52,1 \cdot 03]$ & $1 \cdot 32[0.88,1 \cdot 76]$ & $1.47[0.96,1.98]$ \\
\hline Direct effect & $0.57[0.08,1 \cdot 05]$ & $0.65[0.39,0 \cdot 91]$ & $1 \cdot 24[0 \cdot 80,1 \cdot 69]$ & $1.41[0.90,1 \cdot 93]$ \\
\hline Indirect effect & $-0.05[-0 \cdot 18,0 \cdot 08]$ & $0 \cdot 13[0 \cdot 03,0 \cdot 22]$ & $0.08[-0 \cdot 05,0 \cdot 20]$ & $0.06[-0.09,0 \cdot 20]$ \\
\hline \multicolumn{5}{|l|}{ Full Time Student } \\
\hline Total effect & $0.39[-0.24,1 \cdot 02]$ & $0.34[-0.02,0.71]$ & $0.54[-0.09,1 \cdot 18]$ & $0.65[-0 \cdot 10,1 \cdot 39]$ \\
\hline Direct effect & $0.51[-0 \cdot 13,1 \cdot 15]$ & $0.57[0.21,0.94]$ & $0.75[0 \cdot 12,1 \cdot 39]$ & $0.87[0 \cdot 12,1 \cdot 62]$ \\
\hline Indirect effect & $-0 \cdot 12[-0 \cdot 25,0 \cdot 01]$ & $-0.23[-0.33,-0.13]$ & $-0.21[-0.34,-0.08]$ & $-0.22[-0.37,-0.08]$ \\
\hline \multicolumn{5}{|c|}{ Parent Highest Qualification } \\
\hline \multicolumn{5}{|c|}{ Higher National Certificate/Diploma } \\
\hline Total effect & $0.05[-0 \cdot 22,0 \cdot 32]$ & $0.07[-0.08,0.21]$ & $0 \cdot 14[-0 \cdot 11,0 \cdot 40]$ & $0.02[-0 \cdot 27,0 \cdot 30]$ \\
\hline Direct effect & $0.06[-0 \cdot 21,0 \cdot 33]$ & $0.05[-0 \cdot 10,0 \cdot 20]$ & $0 \cdot 12[-0 \cdot 13,0 \cdot 38]$ & $0 \cdot 01[-0 \cdot 28,0 \cdot 30]$ \\
\hline Indirect effect & $-0.01[-0.08,0 \cdot 05]$ & $0.02[-0.06,0.09]$ & $0.02[-0.06,0 \cdot 10]$ & $0.01[-0.09,0 \cdot 10]$ \\
\hline
\end{tabular}


Table 3 The pathway from parental socioeconomic position to abnormal/doubtful child development via birth factors ${ }^{\mathrm{a}}$ (Continued)

\begin{tabular}{|c|c|c|c|c|}
\hline & Gross Motor Skills & Hearing \& Language & Vision \& Fine Motor Skills & Social \\
\hline & $\beta[\mathrm{Cl}]$ & $\beta[\mathrm{Cl}]$ & $\beta[\mathrm{Cl}]$ & $\beta[\mathrm{Cl}]$ \\
\hline \multicolumn{5}{|c|}{ Highers/Certificate of Sixth Year Studies } \\
\hline Total effect & $0.04[-0 \cdot 20,0 \cdot 29]$ & $0 \cdot 12[-0.01,0.25]$ & $0.20[-0.03,0.43]$ & $-0.09[-0 \cdot 36,0 \cdot 17]$ \\
\hline Direct effect & $0.07[-0 \cdot 18,0.32]$ & $0 \cdot 10[-0 \cdot 03,0 \cdot 24]$ & $0 \cdot 17[-0.06,0 \cdot 40]$ & $-0.09[-0 \cdot 36,0 \cdot 17]$ \\
\hline Indirect effect & $-0.03[-0.09,0 \cdot 04]$ & $0.02[-0.06,0.09]$ & $0.03[-0.05,0 \cdot 11]$ & $0.00[-0.09,0.09]$ \\
\hline \multicolumn{5}{|c|}{ Ordinary Grade/Standard Grade } \\
\hline Total effect & $0.27[0.04,0 \cdot 50]$ & $0.33[0 \cdot 21,0 \cdot 46]$ & $0.43[0 \cdot 21,0 \cdot 65]$ & $0 \cdot 13[-0 \cdot 12,0 \cdot 37]$ \\
\hline Direct effect & $0 \cdot 30[0 \cdot 06,0 \cdot 54]$ & $0.25[0 \cdot 12,0 \cdot 38]$ & $0.32[0 \cdot 10,0 \cdot 54]$ & $0.06[-0 \cdot 19,0 \cdot 31]$ \\
\hline Indirect effect & $-0.03[-0 \cdot 11,0 \cdot 04]$ & $0.08[0 \cdot 01,0 \cdot 16]$ & $0 \cdot 10[0 \cdot 02,0 \cdot 19]$ & $0.06[-0.04,0 \cdot 16]$ \\
\hline \multicolumn{5}{|l|}{ No Qualifications } \\
\hline Total effect & $0.45[0 \cdot 16,0 \cdot 74]$ & $0.59[0.44,0 \cdot 75]$ & $0.86[0 \cdot 60,1 \cdot 11]$ & $0.71[0.42,1 \cdot 00]$ \\
\hline Direct effect & $0.48[0 \cdot 19,0 \cdot 78]$ & $0.44[0 \cdot 29,0 \cdot 60]$ & $0.67[0.41,0.93]$ & $0 \cdot 57[0 \cdot 27,0 \cdot 86]$ \\
\hline Indirect effect & $-0.03[-0.12,0 \cdot 06]$ & $0 \cdot 15[0 \cdot 07,0 \cdot 23]$ & $0.19[0 \cdot 10,0 \cdot 28]$ & $0 \cdot 14[0 \cdot 03,0 \cdot 25]$ \\
\hline
\end{tabular}

Source: SLS

aBased on Model 2 in Table 2. These models also control for maternal marital status. The indirect effect includes birthweight percentile, pre-term indicator, sex, maternal smoking history, mode of delivery, APGAR score, parity, year of admission, maternal age, maternal height, and pre-eclampsia indicator

\section{Discussion}

For most children there appears to be no notable socioeconomic pathway through in utero development. However, for children in households in the most socioeconomically challenging situations there is evidence of a small but notable effect. Children growing up in circumstances of socioeconomic disadvantage, manifested through parental occupation and parental education, were more likely to experience abnormal or doubtful vision and fine motor, social, and hearing and language development. Deficits in gross motor skills were not associated with parental occupation but were very slightly more likely among children of parents without educational qualifications or whose highest qualification was $\mathrm{O}$ Grade/S Grade. The findings of this study are consistent with Dammann et al. [26] who observed an association between socioeconomic background and intelligence and language skills but not visuomotor development. More recently, Hung et al. identified that children born to socioeconomically disadvantaged parents were more likely to exhibit neurological abnormalities and that this could not be explained by differences in perinatal factors [1]. A meta-analysis of studies investigating gross motor skills and socioeconomic background suggested that findings were inconsistent [27].

The longitudinal dataset created in this study contains information on fetal environment, child development measures, and parental socioeconomic position. MM Black, CR Hess and J Berenson-Howard [28] note that gaps in development by socioeconomic position are typically first observed in toddlerhood. The use of information from a number of reviews from 6 to 8 weeks to 48 months increases the likelihood of correctly measuring development and reduces the problems associated with a single point of observation. A further advantage of using the Scottish Longitudinal Study over other cohort or longitudinal survey datasets is that there is very little loss to follow up. There is also an established history of linking Scottish Morbidity Record (SMR) health data to the SLS. Many previous studies on child development have been based on small sample sizes. Using the SLS is much lower cost and use of secondary data minimises intrusion for data subjects.

The findings of this study suggest that children growing up in circumstances of disadvantage are more likely to have poor development outcomes and this is consistent with other studies [29]. The causal pathways for this relationship are not clear though [30]. It is plausible that socioeconomic disparities in brain structure may explain part of this association [30] and this offers a potential avenue for future study. We cannot identify from the information available within this study where the cause of abnormal or doubtful development was due to genetic conditions or lifestyle factors that pre-date birth (such as alcohol use or use of other drugs which may be detrimental during pregnancy). The developmental measures analysed in this study may be indicative of poor or delayed cognitive skills but also of chronic disabling conditions. N Spencer and L Strazdins [31] and CM Blackburn, NJ Spencer and JM Read [32] have identified an association between socioeconomic disadvantage in early childhood and subsequent development of chronic disabling conditions. What this study may also suggest is that the environment in which children grow up is consequential and that family behaviours differ [33]. Differences in access to resources such as nutrition, access to health care, housing cognitively stimulating materials 
and experiences and parental expectations and styles have been proposed as possible reasons for the gradient in child development by socioeconomic position [4]. Differential exposure to stress and coping responses to stress are another feasible explanation for the socioeconomic gradient in child development outcomes [4].Without further information on factors occurring in the early years of a child's life, it is challenging to investigate how these factors moderate, mediate and transact to affect the relationship between socioeconomic position and child development [33].

\section{Limitations}

There is nonresponse within the datasets, particularly with respect to developmental reviews. Wood et al. audited the coverage of CHSP-PS reviews and concluded that there is a progressive decline in review coverage from first to the later reviews and that coverage is lower among deprived groups [34]. However, this has not changed over time. The child development assessments are carried out by a public health visitor and may be used to indicate that a child should be referred as requiring additional support needs. There is a possibility that there may be some misestimation of the underlying condition if the health visitor observes a behaviour but judges that additional support needs will be required or if a health visitor assessment is influenced by the parental socioeconomic position or the child's perinatal history.

Parental occupation and highest qualification are recorded in the 2001 census. These are a proxy for life circumstances and may not perfectly reflect the exact circumstances for young people in their early years. However, the use of the highest occupation or qualification attained for parents is a fairly reliable indicator of general socioeconomic position.

The specification of the mediation model sought to distinguish the indirect effects of a range of measures of fetal environment relative to post-natal effects of the socioeconomic position context. The measures of fetal environment used in this study (including birthweight and gestational age) will not capture all in utero insults and shocks and therefore we may have inadvertently attributed some in utero effects to post-natal environment because maternal behaviour and environment pre and post-natal are likely to be correlated. We may have therefore under estimated the in utero socioeconomic effect. We do not perceive there to be a reverse causation problem as child development occurs after birth. Whilst there may be some omitted variables bias, we have sought to overcome this by the inclusion of many potential confounders and the use of longitudinal data models. Examples of potential confounders might include measures of mother's mental health, maternal and child nutrition, parenting patterns, or domestic violence among others. The administrative datasets linked as part of this study did not include indicators covering such measures but future studies might investigate in greater detail these factors, if available.

\section{Conclusions}

After adjustment for measures of fetal environment, socioeconomic position was a strong predictor of development of hearing and language, vision and fine motor skills, and social skills but not gross motor skills. For most children this gradient appears to be produced not in utero but either differences in early life environment or possibly a pathway affecting both a mother's socioeconomic position and her offspring's development (e.g. genetic/epigenetic). For children of parents with no educational qualification, a poor fetal environment does appear to make a major contribution to the chance of child development abnormalities but the majority of the effect still appears to be through the post-natal environment.

In order to tackle socioeconomic inequalities in child development for most children, a focus on differences in early life environments may be most important. For children in the poorest socioeconomic position interventions should also focus on both early life environment and the health and behaviours of mothers during pregnancy. Future research should examine other factors in early childhood that may influence child development, such as antenatal and postnatal stress [35], to explore whether these mediate the relationship between socioeconomic disadvantage and child development.

\section{Endnotes}

${ }^{1}$ For details, see: http://www.isdscotland.org/HealthTopics/Child-Health/Child-Health-Programme/ChildHealth-Systems-Programme-Pre-School.asp accessed 01/ 03/17.

${ }^{2}$ For further details, see http://www.isdscotland.org/ Health-Topics/Child-Health/Child-Health-Programme/ Child-Health-Systems-Programme-Pre-hall4.asp accessed 26/09/17.

${ }^{3}$ Whilst this test assumes independence between observations, the broad indication of trend merits further investigation using panel data models reported in Tables 3-6 to correctly adjust for the variance structure.

${ }^{4}$ For the results of a sensitivity analysis using birthweight categories instead of birthweight percentiles see Additional file 1: Table S7.

\section{Additional file}

Additional file 1: Table S1. Child Health Surveillance Programme- Preschool review coverage. Table S2. Descriptive statistics of the association between socioeconomic position and fetal environment measures. Table S3. 
Tests of independence between measures of socioeconomic position and fetal environment. Table S4. Random effects logistic regression models of development measures with fetal environment (including birthweight percentile). Table S5. Random effects logistic regression models of development measures with fetal environment (including birthweight) Table S6. Random effects logistic regression models of development measures with socioeconomic position and fetal environment (including estimates not reported in Table 2). Table S7. Random effects logistic regression models of development measures with socioeconomic position and fetal environment (sensitivity analysis using birthweight) Table S8. Random effects logistic regression models of development measures with socioeconomic position and fetal environment for males and females (1). Table 59. Random effects logistic regression models of development measures with socioeconomic position and fetal environment for males and females (2). (DOCX $67 \mathrm{~kb}$ )

\section{Abbreviations}

CHSP-PS: Child Health Surveillance Programme - Pre School dataset; ISD: NHS Scotland Information Services Division; KHB: Karlson-Holm-Breen method; LBW: Low Birthweight; NS-SEC: National Statistics Socio Economic Class; SLS: Scottish Longitudinal Study; SMR: Scottish Morbidity Record; SMR02: Scottish Morbidity Record maternity inpatient and day case dataset

\section{Acknowledgements}

The help provided by staff of the Longitudinal Studies Centre - Scotland (LSCS) is acknowledged.

\section{Funding}

This work was supported by a grant from the Wellcome Trust (The Scottish Health Informatics Programme-Ref WT086113) and the Economic and Social Research Council (grant numbers ES/L007487/1 and ES/1025561/3). The LSCS is supported by the ESRC/JISC, the Scottish Funding Council, the Chief Scientist's Office and the Scottish Government. The author is responsible for the interpretation of the data. Census output is Crown copyright and is reproduced with the permission of the Controller of HMSO and the Queen's Printer for Scotland.

\section{Availability of data and materials}

De-identified linked administrative data were used in this project. The data are linked using a third party (NHSCR) and at no time is any name or address data available to the SLS unit. The project was approved by the NHS National Services Scotland Privacy Advisory Committee. Access to SLS data and programming code is restricted to SLS users due to data confidentiality. For further details, please see: http://sls.lscs.ac.uk/about/what-about-dataconfidentiality/

\section{Authors' contributions}

CD and LW applied for the administrative data linkage. CD helped design the analyses and LW prepared the data for analysis. CP analysed the data and drafted the manuscript. CD \& LW contributed to writing and editing the manuscript. All authors read and approved the final manuscript.

\section{Ethics approval and consent to participate}

The Geography and Geoscience School Ethics Committee - part of the University Teaching and Research Ethics Committee (UTREC) at the University of St Andrews. Ethics Reference No. GG7149. Consent to participate is not required because the data have been de-identified by a third party (NHSCR). The data linkage was approved by the NHS National Services Scotland Privacy Advisory Committee.

\section{Consent for publication}

Not applicable.

\section{Competing interests}

The authors declare that they have no competing interests.

\section{Publisher's Note}

Springer Nature remains neutral with regard to jurisdictional claims in published maps and institutional affiliations.

\section{Author details}

${ }^{1}$ Department of Sociology, University of Exeter, Exeter, UK. ${ }^{2}$ Administrative Data Research Centre - Scotland, Edinburgh, UK. ${ }^{3}$ School of Geosciences, University of Edinburgh, Edinburgh, UK.

Received: 31 May 2017 Accepted: 8 November 2017

Published online: 22 November 2017

\section{References}

1. Chin-Lun Hung G, Hahn J, Alamiri B, Buka SL, Goldstein JM, Laird N, Nelson CA, Smoller JW, Gilman SE. Socioeconomic disadvantage and neural development from infancy through early childhood. Int J Epidemiol. 2015; 44(6):1889-99.

2. Ozal C, Bayoglu B, Kerem Gunel M, Karahan S, Anlar B. Effects of socioeconomic status and maternal education on gross motor development of preschool children. Developmental Medicine \& Child Neurology. 2015;57:55-6.

3. Gottschling-Lang A, Franze M, Hoffmann W. Associations of motor developmental risks with the socioeconomic status of preschool children in north-eastern Germany. Child Development Research 2013, Article ID. 790524:6.

4. Bradley RH, Corwyn RF. Socioeconomic status and child development. Annu Rev Psychol. 2002;53(1):371-99.

5. Nicholson JM, Lucas N, Berthelsen D, Wake M. Socioeconomic inequality profiles in physical and developmental health from 0-7 years: Australian National Study. J Epidemiol Community Health. 2010;

6. Shenkin SD, Starr JM, Deary IJ. Birth weight and cognitive ability in childhood: a systematic review. Psychol Bull. 2004;130(6):989-1013.

7. de Kieviet JF, Piek JP, Aarnoudse-Moens CS, Oosterlaan J. Motor development in very preterm and very low-birth-weight children from birth to adolescence: a meta-analysis. JAMA : the journal of the American Medical Association. 2009:302(20):2235-42.

8. Olusanya BO. Perinatal profile of very low birthweight infants under a universal newborn hearing screening programme in a developing country: a case-control study. Developmental neurorehabilitation. 2010;13(3):156-63.

9. Williamson KE, Jakobson LS. Social perception in children born at very low birthweight and its relationship with social/behavioral outcomes. Journal of child psychology and psychiatry, and allied disciplines. 2014;55(9):990-8.

10. Arpi E, Ferrari F. Preterm birth and behaviour problems in infants and preschool-age children: a review of the recent literature. Dev Med Child Neurol. 2013;55(9):788-96.

11. Bhutta AT, Cleves MA, Casey PH, Cradock MM, Anand KJ. Cognitive and behavioral outcomes of school-aged children who were born preterm: a meta-analysis. JAMA : the journal of the American Medical Association. 2002;288(6):728-37.

12. Bos AF, Van Braeckel KN, Hitzert MM, Tanis JC, Roze E. Development of fine motor skills in preterm infants. Dev Med Child Neurol. 2013;55(Suppl 4):1-4

13. Rubio-Codina M, Attanasio O. Grantham-McGregor S: mediating pathways in the socio-economic gradient of child development: evidence from children 6-42 months in Bogota. Int J Behav Dev. 2016;40(6):483-91.

14. Blumenshine P, Egerter S, Barclay CJ, Cubbin C, Braveman PA. Socioeconomic disparities in adverse birth outcomes: a systematic review. Am J Prev Med. 2010:39(3):263-72.

15. Moser K, Li L, Power C. Social inequalities in low birth weight in England and Wales: trends and implications for future population health. J Epidemiol Community Health. 2003;57(9):687-91.

16. Boyle PJ, Feijten P, Feng Z, Hattersley L, Huang Z, Nolan J, Raab G. Cohort profile: the Scottish longitudinal study (SLS). Int J Epidemiol. 2009:38(2):385-92.

17. Riordan DV, Morris C, Hattie J, Stark C. Family size and perinatal circumstances, as mental health risk factors in a Scottish birth cohort. Soc Psychiatry Psychiatr Epidemiol. 2012;47(6):975-83.

18. Barber JH, Boothman R, Paget-Stanfield J. A new visual chart for pre-school developmental screening. Health Bulletin (Edinburgh). 1976;34(2):80-91.

19. NHS Scotland: Child health surveillance Programme pre-school clinical guidelines. In. Edinburgh: NHS Scotland; 2010

20. Galobardes B, Shaw M, Lawlor DA, Lynch JW. Indicators of socioeconomic position (part 2). J Epidemiol Community Health. 2006;60(2):95-101.

21. Galobardes B, Shaw M, Lawlor DA, Lynch JW. Indicators of socioeconomic position (part 1). J Epidemiol Community Health. 2006;60(1):7-12.

22. Bonellie S, Chalmers J, Gray R, Greer I, Jarvis S, Williams C. Centile charts for birthweight for gestational age for Scottish singleton births. BMC Pregnancy and Childbirth. 2008;8(1):5. 
23. Boyle EM, Poulsen G, Field DJ, Kurinczuk JJ, Wolke D, Alfirevic Z, Quigley MA. Effects of gestational age at birth on health outcomes at 3 and 5 years of age: population based cohort study. BMJ. 2012;344:1-14.

24. Breen R, Karlson KB, Holm A. Total, direct, and indirect effects in logit and Probit models. Sociol Methods Res. 2013;42(2):164-91.

25. Goldthorpe JH, McKnight A. The economic basis of social class. In: Morgan SL, Grusky DB, Fields G, editors. Mobility and Inequality: Frontiers of Research in Sociology and Economics. Edn. Stanford, CA: Stanford University Press; 2006. p. 109-36.

26. Dammann O, Walther H, Allers B, Schroder M, Drescher J, Lutz D, Veelken N, Schulte FJ. Development of a regional cohort of very-low-birthweight children at six years: cognitive abilities are associated with neurological disability and social background. Dev Med Child Neurol. 1996;38(2):97-106.

27. Barnett LM, Lai SK, Veldman SLC, Hardy LL, Cliff DP, Morgan PJ, Zask A, Lubans DR, Shultz SP, Ridgers ND, et al. Correlates of gross motor competence in children and adolescents: a systematic review and metaanalysis. Sports Med. 2016:1-26.

28. Black MM, Hess CR, Berenson-Howard J. Toddlers from low-income families have below normal mental, motor, and behavior scores on the revised Bayley scales. J Appl Dev Psychol. 2000;21(6):655-66.

29. Brooks-Gunn J, Duncan GJ. The effects of poverty on children. Futur Child. 1997:7(2):55-71.

30. Brito NH, Noble KG. Socioeconomic status and structural brain development. Front Neurosci. 2014;8:276.

31. Spencer N, Strazdins L. Socioeconomic disadvantage and onset of childhood chronic disabling conditions: a cohort study. Arch Dis Child. 2015;100(4):317-22.

32. Blackburn CM, Spencer NJ, Read JM. Is the onset of disabling chronic conditions in later childhood associated with exposure to social disadvantage in earlier childhood? A prospective cohort study using the ONS longitudinal study for England and Wales. BMC Pediatr. 2013;13(1):1-7.

33. Engle PL, Black MM. The effect of poverty on child development and educational outcomes. Ann N Y Acad Sci. 2008;1136(1):243-56.

34. Wood R, Stirling A, Nolan C, Chalmers J, Blair M. Trends in the coverage of 'universal' child health reviews: observational study using routinely available data. BMJ Open. 2012;2(2)

35. Talge NM, Neal C, Glover V. The early stress TR, prevention science network $\mathrm{F}$, neonatal experience on $\mathrm{C}$, adolescent mental $\mathrm{H}$ : antenatal maternal stress and long-term effects on child neurodevelopment: how and why? J Child Psychol Psychiatry. 2007;48(3-4):245-61.

\section{Submit your next manuscript to BioMed Central and we will help you at every step:}

- We accept pre-submission inquiries

- Our selector tool helps you to find the most relevant journal

- We provide round the clock customer support

- Convenient online submission

- Thorough peer review

- Inclusion in PubMed and all major indexing services

- Maximum visibility for your research

Submit your manuscript at www.biomedcentral.com/submit

) Biomed Central 